\title{
Aplikasi Sistem Informasi Koperasi Simpan Pinjam Dengan Metode Incremental
}

\author{
Noor Hasan ${ }^{1}$, Wahyu Eko Susanto ${ }^{2}$ \\ Universitas Bina Sarana Informatika \\ noor.nhs@bsi.ac.id ${ }^{1}$, wahyu.wes@bsi.ac.id ${ }^{2}$
}

\begin{abstract}
Abstrak - Dari penelitian sebelumnya menunjukkan trend koperasi yang gagal semakin meningkat pada taun 2014 saja ada sekitar $40 \%$ koperasi yang tidak aktif. Dimana salah satu faktor yang berpengaruh terhadap koperasi yang tidak aktif adalah kurangnnya penggunaan teknologi. Hal ini sejalan dengan data penggunaan teknologi informasi oleh koperasi Di indonesia yang hanya berkisar antara $25 \%$ sampai $30 \%$ yang menunjukkan penerapan teknologi di perkoperasian masih minim. Termasuk di dalamnya adalah koperasi simpan pinjam. Oleh karenanya perlu di buatkan sebuah aplikasi yang mamapu membantu koperasi dalam menjalanjan proses bisnisnya. Sehingga dapat meningkatkan serapan penggunaan teknologi pada koperasi dan mengurangi resiko kegagalan koperasi. Metode pengembangan perangkat lunak yang di gunakan pada Sistem informasi koperasi simpan pinjam adalah metode incremental. Hasil dari pembuatan aplikasi ini menunjukan Metode incremental bisa diterapkan dalam pembangunan sistem informasi koperasi Simpan Pinjam. Langkahlangkah di metode Incremental memudahkan dalam pengembangan Aplikasi karena langkah langkah dalam metode ini runtut dan sistematis. Hasil pengujian menggunakan Metode Black Box testing yang dilakukan terhadap sistem informasi koperasi menunjukkan semua fungsionalitas sistem dapat berjalan dengan baik. Selain menunjukkan fungsionalitas sistem berjalan dengan baik Pengujian juga menunjukkan bahwa sistem yang di hasilkan sudah dapat memenuhi kebutuhan pengguna sesuai dengan Analisa Kebutuhan perangkat lunak.
\end{abstract}

Kata Kunci : Koperasi, Sistem Informasi, Incremental.

Abstract - The Previous research shows that the trend of failed cooperatives has increased in 2014 alone, around $40 \%$ of cooperatives are inactive. Where one of the factors that influence an inactive cooperative is the lack of use of technology. This is in line with data on the use of information technology by cooperatives in Indonesia, which only ranges from $25 \%$ to $30 \%$, which shows the application of technology in cooperatives is still minimal. This includes savings and loan cooperatives. Therefore it is necessary to make an application that is able to assist cooperatives in running their business processes. So as to increase the uptake of the use of technology in cooperatives and reduce the risk of cooperative failure. The software development method used in the savings and loan cooperative information system is the incremental method. The results of making this application show that incremental methods can be applied in the construction of savings and loan cooperative information systems. The steps in the Incremental method make it easy in Application development because the steps in this method are coherent and systematic. The results of testing using the Black Box testing method performed on cooperative information systems show that all system functionalities can work well. In addition to showing the functionality of the system is running well Testing also shows that the system produced has been able to meet user needs in accordance with the Analysis of Software Requirements..

Keywords: Koperasi , Information Systems, Incremental

\section{PENDAHULUAN}

Seperti yang telah kita ketahui bersama bahwa koperasi merupakan soko guru perekonomian indonesia, oleh karenanya keberadaan koperasi di jamin oleh pemerintah yang di tuangkan dalam undang-undang nomor 25 tahun 1992 pasal 4. Yang salahsatu isinya menjelaskan bahwa koperasi "Memperkokoh perekonomian rakyat sebagai dasar kekuatan dan ketahanan perekonomian nasional dengan koperasi sebagai soko gurunya." (Zulhartati, 2010) Di tengah pentingnya peranan koperasi sebagai salah satu faktor penyokong perekonomian indonesia, justru trend koperasi yang gagal semakin meningkat pada taun 2014 saja ada sekitar $40 \%$ koperasi yang tidak aktif. (Andriani, 2015)

Disebutkan bahwa salah satu faktor yang berpengaruh terhadap koperasi yang tidak aktif adalah kurangnnya penggunaan teknologi dalam manajemen operasional koperasi (Febriantika, 2016). Hal ini sejalan dengan data penggunaan teknologi informasi oleh koperasi $\mathrm{Di}$ indonesia bahwa koperasi yang menggunakan teknologi informasi dalam proses bisnisnya hanya berkisar antara $25 \%$ sampai 
30\% (Silaban, 2019). Ini menunjukkan penerapan teknologi di perkoperasian masih minim.

Koperasi Simpan Pinjam (KSP) merupakan salah satu bentuk dari Koperasi yaitu Koperasi yang menjalankan usaha simpan pinjam untuk anggotanya. (Anggoro et al., 2015) Dimana kegiatan usahanya berupa melakukan kegiatan mikro finance yaitu menghimpun serta menyalurkan yang berasal dari anggota koperasi dan di salurkan ke anggota koperasi tersebut. (Ramdhani \& Lantin, 2016). Atau sering kita kenal dengan Koperasi simpan pinjam.

Dari penelitian sebelumnya dan uraian permasalahan di atas yang menempatkan penggunaan teknologi sebagai salah satu faktor yang berpengaruh terhadap kegagalan suatu koperasi. dapat di simpulkan bahwa sebuah koperasi perlu mengadopsi atau menggunakan teknologi dalam hal ini teknologi informasi untuk menjalankan proses manajerialnya. Hal ini bertujuan agar dapat mengurangi resiko kegagalan pada koperasi tersebut

1. Landasan Teori

\section{a. Sistem Informasi}

Sistem informasi sendiri dapat di definisikan sebagai gabungan dari proses mengumpulkan, memanipulasi, menyimpan dan mengirimkan baik berupa data atau informasi sehingga dapat menciptakan suatu rekasi untuk memperoleh suatu tujuan (Raharjana, 2017)

b. Koperasi

Undang-Undang No.25/1992 pada pasal 1 menjelaskan bahwa koperasi adalah suatu badan usaha yang lebih memiliki dasar asas kekeluargaan. (Anggoro et al., 2015). Sedangkan berdasarkan jenisnya menurut PP No.60/1959 Pasal 2 koperasi dibedakan menjadi 7 jenis yaitu (Sattar, 2017): 1) koperasi Desa; 2). Koperasi Pertanian; 3). Koperasi Peternakan; 4). Koperasi Perikanan; 5) Koperasi Kerajinan/Industri; 6) Koperasi Simpan Pinjam; 7) Koperasi Konsumsi.

Secara ringkas koperasi simpan pinjam didefinisikan sebagai koperasi yang melakukan kegiatan jasa pada bidang penerimaan simpanan dana dari anggota yang selanjutnya dipinjamkan dana tersebut di pinjamkan kepada anggota koperasi. (Anggoro et al., 2015)

\section{c. Bahasa Pemrograman}

Bahasa pemrograman yang di gunakan dalam pengembangan aplikasi ini menggunakan PHP, Java Script, CSS dengan bahasa SQL.

\section{METODOLOGI PENELITIAN}

\section{Metode Pengumpulan Data}

Teknik pengumpulan data digunakan untuk memperoleh data-data yang dibutuhkan dalam pembuatan sistem. Adapun teknik pengumpulan data yang digunakan antara lain:

\section{a. Analisa Dokumen}

Pada penelitian in untuk mendukung data yang di perlukan dalam penelitian di lakukan analisa dokumen yang terkait langsung dengan proses bisnis. Seperti Buku tabungan, Formulir permohonan pinjaman, Data Staf, Formulir pendaftaran anggota, Form Pembayaran Pinjaman.

b. Wawancara

Pengumpulan data pada proses waancara. Bertemu langsung dengan pimpinan koperasi untuk mengetahui secara detail mengenai proses bisnis simpan pinjam yang ada di koperasi "Waluyo Sejati"

c. Studi Literatur

Penelitian sebelumnya dengan judul "Sistem Informasi Laporan Keuangan Pada Koperasi Simpan Pinjam Kelurahan Gunung menggunakan UML" . Yang di terbitkan oleh " Jurnal Idealis Vol .1 No. 1 , Maret 2018 " bahwa dalam penelitian ini peneliti mencoba memberikan solusi untuk mengurangi kesalahan pencatatan transaksi dengan menciptakan aplikasi Simpan pinjam dengan menggunakan Microsoft Visual Basic 2008 dan memanfaatkan database mysql. (Christianti \& Ariesta, 2018)

Pada penelitian yang lainnya yang berjudul "Sistem Informasi Simpan Pinjam Berbasis Website Koperasi "RikRik Gemi" SMKN 15 Bandung". Yang dipublikasikan pada Jurnal INFORMATIKA, Vol. 3 September 2016. Bahwa dalam penelitian tersebut menunjukkan bahwa pencatatan transaksi masih menggunakan cara konvensional dengan menggunakan buku dan Microsoft Excel sehingga transaksi simpan pinjam menjadi tidak efektif. Dan dibuat aplikasi berbasis web dan MySql namun ada beberapa fitur yang belum dilengkapi salahsatunya adalah laporan masuk dan keluarnya. (Ramdhani \& Lantin, 2016)

\section{Metode Pengembangan Perangkat Lunak}

Selain metode pengumpulan data dalam penelitian ini juga memerlukan metode pengembangan perangkat lunak karena hasil akhir dari penelitian ini adalah menghasilkan sebuah aplikasi. Dengan menerapkan metode pengembangan perangkat lunak, maka dalam pengembangan aplikasi akan menjadi lebih mudah dalam setiap tahapannya. Adapun metode pengebangan perangkat lunak yang di gunakan dalam penelitian ini adalah metode incremental.

Metode incremental dipilih karena metode ini memiliki fleksibilitas dan resiko yang lebih kecil dalam pengembangan sistem di banding dengan metode yang lainnya (Syarif \& Nugraha, 2019). Dan metode ini juga memiliki 
keunggulan pada proses yang pararel sehingga antar tahapan tidak harus selalu saling menunggu (Susanto \& Andriani, 2018).

Pengembagan setiap versi merupakan versi terakhir dari pengembangan sebelumnya yang dinaikkan kemampuannya atau dengan tambahan baru. Metode ini memiliki kemampuan untuk melayani pengguna serta memungkinkan pengguna untuk ikut mengevaluasi aplikasi (Waseso et al., 2018). Pada gambar 1 berikut diperlihatkan diagram dari metode incremental.

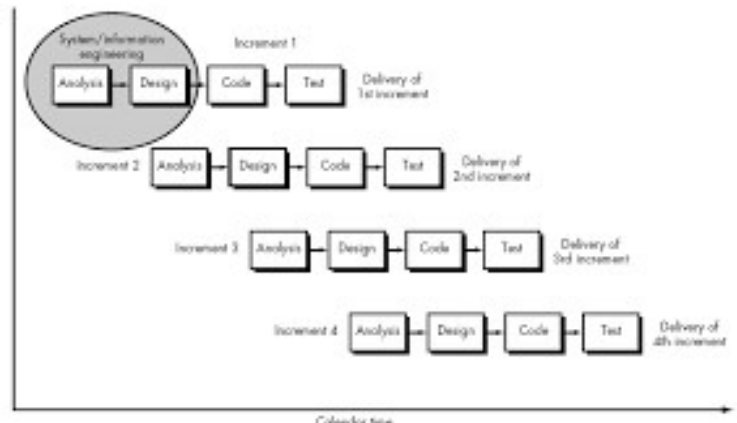

Gambar 1. Model Incremental

\section{HASIL DAN PEMBAHASAN}

1. Perencanaan Sistem

a. Kebutuhan Fungsional

1) Input

a) Kepala koperasi data melakukan pengelolan data baik penambahan baru, penghapusan, perubahan data termasuk level Akses. Serta melakukan validasi pinjaman.

b) Petugas, dapat melakukan pengolahan data Nasabah, Pengajuan Pinjaman Maupun penerimaan Simpanan dari Nasabah.

c) Bendahara, dapat melakukan pengelolaan kas berkaitan dengan validasi pinjaman dan dana simpanan.

2) Output

a) Sistem dapat menampilkan data nasabah untuk di validasi petugas, menampilkan laporan keuangan.

b) Sistem dapat Menyajikan informasi nasabah yang mengajukan pinjaman kepada ketua koperasi dan bendahara untuk di validasi.

c) Sistem dapat menampilkan fasilitas pada dashboard sesuai dengan hak aksesnya.

3) Process

a) Sistem melakukan autentifikasi data kemudian memvalidasi hak akses user.

b) Sistem dapat melakukan menampilkan kondisi keuangan koperasi ketika ada transaksi. c) Kepala Koperasi dapat mengatur hak akses, mengelola data, dan melakukan proses CRUD pada user.

d) Bendahara dan Ketua koperasi dapat melakukan Validasi terhadap pinjaman yang di ajukan.

e) Sistem dapat Menghapus Sesi Ketika user melakukan Logout.

4) Performance

a) Sistem mampu merekam data dan menyimpan dalam basis data sehingga dapat memudahkan temu kembali data.

b) Sistem dapat melakukan validasi berjenjang pada proses pengajuan pinjaman dari Petugas, bendahara sampai kepala Koperasi.

c) Sistem dapat menyimpan log data sehingga dapat di telusur user mana yang melakukan perubahan data pada sistem.

5) Control

Untuk menjamin keamanan dan validitas informasi maka pada sistem di lengkapi autentifikasi berupa Login, semua User harus melakukan login dengan user dan password untuk menju halaman dashbord.

b. Kebutuhan Non Fungsional

1) Ability

Aplikasi sistem Informasi Koperasi ini dapat menyajikan data secara real time kepada user.

2) Reliability

Aplikasi Sistem informasi koperasi ini dapat di akses oleh beberapa user sekaligus dan dapat dilakukan proses secara bersamaan.

3) Ergonomy

Aplikasi Sistem informasi Koperais ini di bangun dengan mempertimbangkan Userfrendly baik perwarnaan, message, font sampai antar muka.

4) Memory

Aplikasi sistem informasi Koperasi ini dibuat seringan mungkin dengan memperhitungkan penggunaan memori pada basis data maupun pemrosesan.

5) Response Time

Aplikasi ini di buat dengan prinsip informasi Real time sehingga ketika ada transaksi yang masuk maka saat itu juga akan di olah dan memberikan feedback informasi kepada user.

6) Communication Language

Bahasa yang di gunakan pada sistem informasi ini menggunakan bahasa Indonesia karena aplikasi ini akan di 
gunakan oleh user yang lebih menguasai bahasa indoensia.

\section{Desain Sistem}

Use Case di gunakan untuk mendeskripsikan proses interaksi sistem informasi dengan aktor pada aplikasi yang akan dibangun. (Fitriani \& Verawati, 2019).

Berikut merupakan usecase diagram dari sistem informasi koperasi simpan pinjam. Diama terdapat 3 aktor dan fungsi-fungsi yang dimiliki oleh masing masing aktor dimana setia aktor harus melakukan login agar dapat menggunakan sistem . Dari diagram usecase ini nanti akan di implementasikan menjadi fungsi pada sistem informasi koperasi impan pinjam. Pada gambar 2 diperlihatkan bentuk usecase diagramnya.

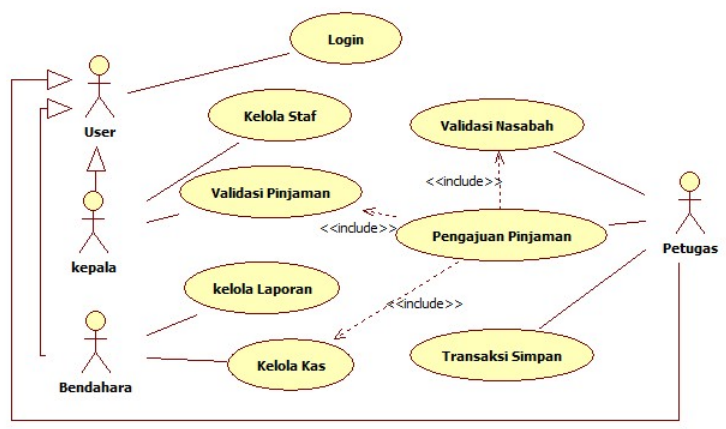

Gambar 2. Usecase Diagram

Selain desain sistem dengan menggunakan usecase diagram, di buat pula desain database sebagai penyimpan data pada sistem informasi. Berikut gambar 4 di tampilkan bentuk desain LRS pada sistem informasi koperasi simpan pinjam

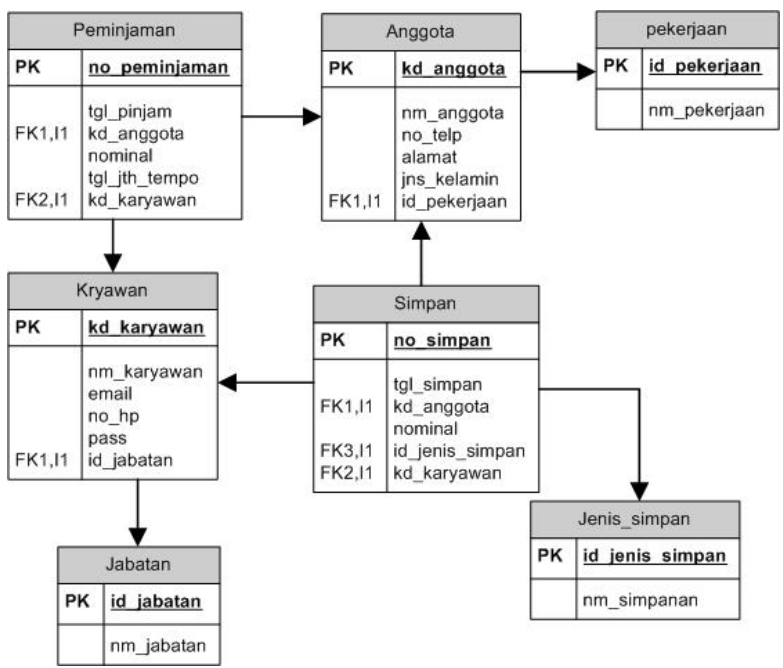

\section{Koding}

Gambar 3. LRS

Hasil dari desain sistem diterjemahkan dalam bentuk koding yang menghasilkan tampilan antarmuka Aplikasi serta perilaku dari sistem sehingga Aplikasi dapat di gunakan sesuai dengan tujuan dari Aplikasi itu sendiri. Berikut bentuk tampilan Antar muka Aplikasi Sistem Informasi Koperasi.

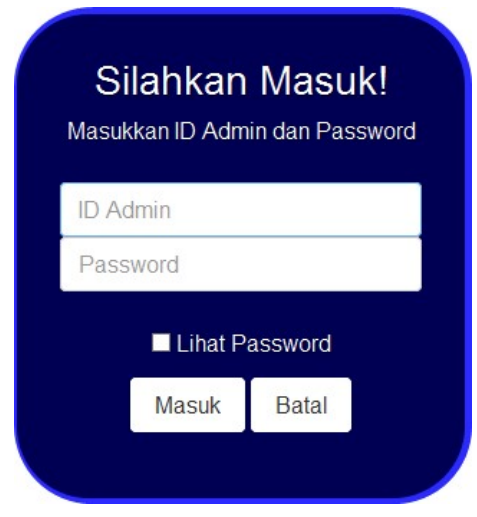

Gambar 4. Login

Halaman Login ini di gunakan untuk otentifikasi user yang akan masuk kedalam sistem. Agar data yang ada dalam sistem dapat dijamin validitasya.

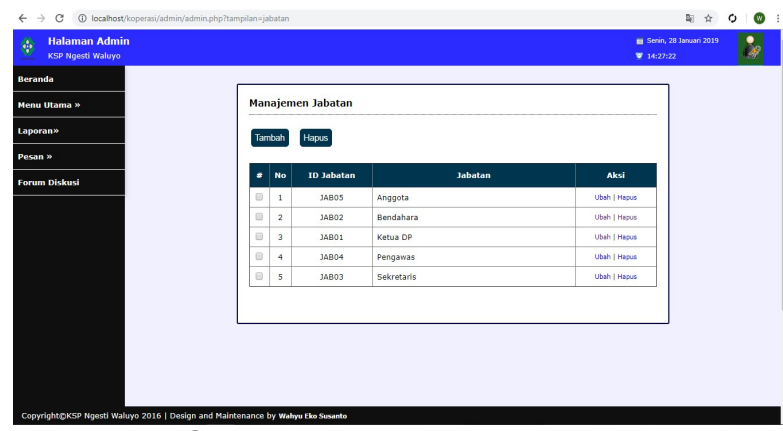

Gambar 5. Kelola Jabatan

Halaman Kelola jabatan di gunakan sebagai pengelolaan jabatan pada KSP Waluyo Sejati , apabila ada penambahan jabatan atau pergantian jabatan dapat di lakukan panambahan den perubahan melalui halaman ini. Perubahan dan penambahan pada halaman ini akan berpengaruh ke hak akses dan nama valdasi pada persuratan.

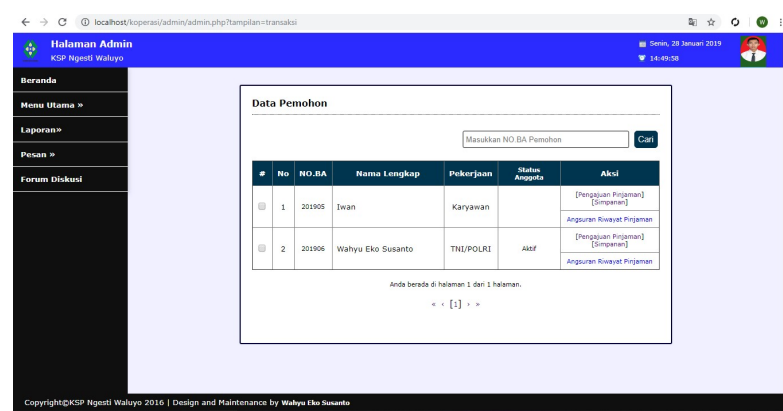

Gambar 6. Transaksi Anggota

Halaman transaksi anggota ini di gunakan oleh staff koperasi untuk melakukan transaksi yang berkaitan dengan simpanan dan pinjaman yang di lakukan oleh anggota koperasi 


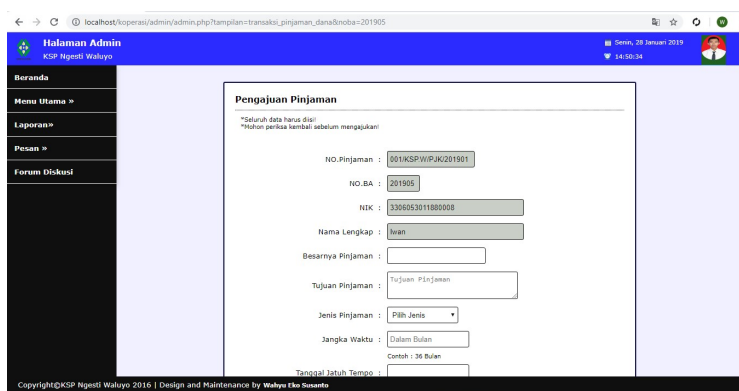

Gambar 7. Pengajuan Pinjaman

Halaman pengajuan pinjaman di gunakan setelah memilih bentuk transaksi pada halaman transaksi anggota aapabila memilih "Pinjaman" maka akan muncul halaman ini untuk melakukan validasi data peminjam dan pengisian data peminjaman.

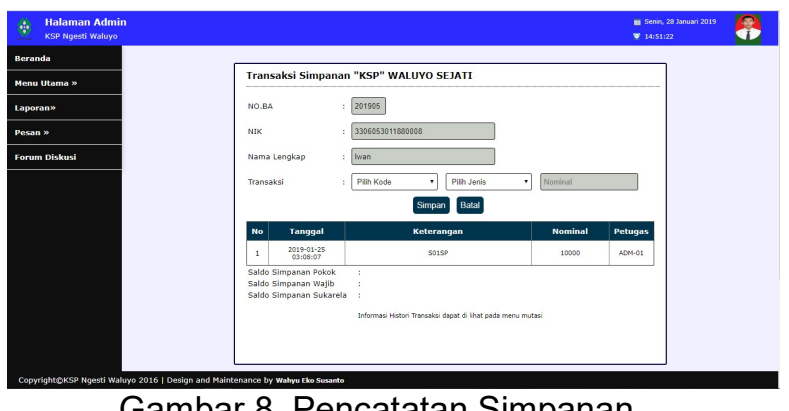

Halaman pencatatan simpanan di gunakan untuk mencatat traksaksi simpanan yang di lakukan oleh anggota koperasi, baik simpanan sukarela, simpanan wajib, maupun penarikan yang lainnya. Pada halaman ini akan terlihat total saldo dan histori transaksi namun hanya di batasi 5 transaksi terakhir.

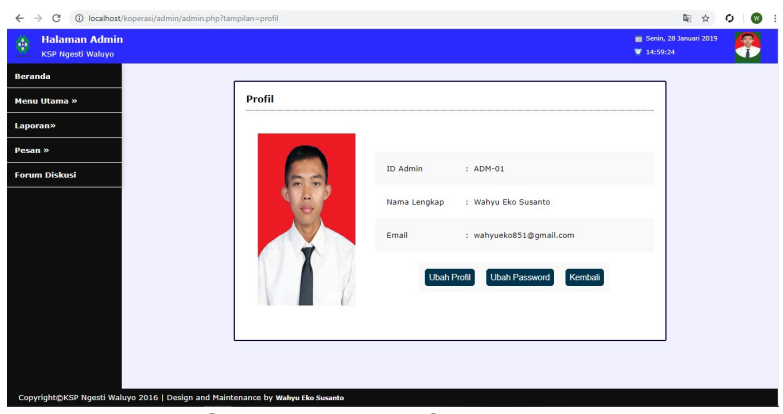

Gambar 9. Profil admin

Halaman profil admin di gunakan untukmelakukan pengelolaan profil dari admin tersebut baik perubahan profil namun terbatas pada data tertentu dan perubahan password. Hasil dari rancangan basis data pada LRS di implementasikan pada aplikasi sehingga di dapatkan hasil pada gambar 10 , berikut ini.

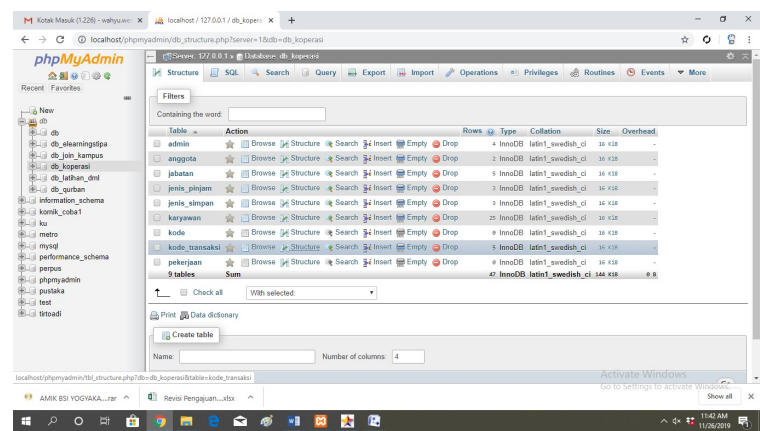

Gambar 10. Database pada PhpMyadmin

\section{Testing}

Setelah Desain di terjemahkan dalam koding, langkah selanjutnya adalah melakukan pengujian. Ini bertujuan untuk memastikan aplikasi yang di hasilkan sesuai dengan rancagan yang di buat dan berfungsi dengan baik.

Tabel 1. Checklist hasil uji fungsionalitas sistem dengan metode blackbox testing

\begin{tabular}{|c|c|c|c|c|c|c|}
\hline \multirow{3}{*}{ Unit } & \multirow{3}{*}{$\begin{array}{c}\begin{array}{c}\text { Tampilan } \\
\text { sesuai }\end{array} \\
\text {. }\end{array}$} & \multirow{3}{*}{$\begin{array}{l}\text { Fungsionalitas } \\
\text { Sesuai }\end{array}$} & Pengujian & \multirow{2}{*}{\multicolumn{3}{|c|}{ Validasi Data }} \\
\hline & & & $\begin{array}{c}\text { Fungsi } \\
\quad\end{array}$ & & & \\
\hline & & & $\begin{array}{l}\text { Manpulasi atata } \\
\text { Sesuai }\end{array}$ & $g$ & Salah & Benar \\
\hline Login & $\checkmark$ & $\checkmark$ & $\sqrt{ }$ & 4 & $\sqrt{ }$ & $\sqrt{ }$ \\
\hline Dashbord user & $\checkmark$ & $\sqrt{ }$ & & - & - & \\
\hline kelola Pinjaman & v & v & $\sqrt{ }$ & v & $\checkmark$ & $\sqrt{ }$ \\
\hline Kelola Simpanan & $\checkmark$ & $\sqrt{ }$ & $\checkmark$ & $\sqrt{ }$ & $\sqrt{ }$ & $\sqrt{ }$ \\
\hline Kelola User & $\sqrt{ }$ & v & $\sqrt{ }$ & v & $\checkmark$ & $\sqrt{ }$ \\
\hline Kelola Nasabah & $\sqrt{ }$ & v & v & v & v & v \\
\hline Kelola Laporan & $\checkmark$ & $\sqrt{ }$ & $\sqrt{ }$ & $\sqrt{ }$ & $\sqrt{ }$ & $\checkmark$ \\
\hline Kelola Kas & $\checkmark$ & v & v & v & v & v \\
\hline
\end{tabular}

\section{KESIMPULAN}

Metode incremental bisa diterapkan dalam pembangunan sistem informasi dalam penelitian ini adalah sistem informasi Koperasi. Langkah-langkah di metode Incremental memudahkan dalam pengembangan Aplikasi karena langkah langkah dalam metode ini runtut dan sistematis. Hasil pengujian menggunakan Metode Black Box testing yang dilakukan terhadap sistem informasi koperasi menunjukkan semua fungsionalitas sistem dapat berjalan dengan baik. Selain menunjukkan fungsionalitas sistem berjalan dengan baik Pengujian juga menunjukkan bahwa sistem yang di hasilkan sudah dapat memenuhi kebutuhan pengguna sesuai dengan Analisa Kebutuhan perangkat lunak.

\section{REFERENSI}

Andriani, A. (2015). Perancangan Sistem Informasi Deteksi Kegagalan Koperasi Di Tingkat Provinsi Berbasis Algoritma C4.5. JNTETI, 25-31.

Anggoro, D., Umar, M. D., Vinanty, E., \& Dananjaya, D. (2015). RANCANGAN SISTEM INFORMASI KOPERASI SIMPAN PINJAM GURU DAN PEGAWAI PADA KOPERASI SMK MANGGALA TANGERANG. SENTIKA, 213-222. 
Christianti, A. L., \& Ariesta, A. (2018). Sistem Informasi Laporan Keuangan Pada Koperasi Simpan Pinjam Kelurahan Gunung Menggunakan UML. Jurnal IDEALIS, 1(1), 481-488.

Febriantika, V. W. (2016). Studi Tentang Faktor-Faktor Penyebab Tidak Aktifnya Koperasi Gotong Royong Kota Blitar. Kebijakan Dan Manajemen Publik.

Fitriani, H., \& Verawati. (2019). SISTEM INFORMASI AKUNTANSI PENDAPATAN JASA PADA WISATA KIMAL PARK KOTABUMI UTARA. ONESISMIK, 1, 94102.

Raharjana, I. K. (2017). Pengembangan Sistem Informasi Menggunakan Metodologi Agile. Deepublish.

Ramdhani, Y., \& Lantin, R. (2016). SISTEM INFORMASI SIMPAN PINJAM BERBASIS WEBSITE KOPERASI RikRik Gemi " SMKN 15. INFORMATIKA, 3(September), 183-190.

Sattar. (2017). Buku Ajar Ekonomi Koperasi. Deepublish.
Silaban, M. W. (2019). Koperasi di Era Revolusi Industri 4.0 Didorong Terapkan Teknologi Digital. Tempo. https://bisnis.tempo.co/read/1220743/kope rasi-di-era-revolusi-4-0-didorong-terapkanteknologi-digital

Susanto, A., \& Andriani, A. (2018). Sistem Informasi "Bantara" Untuk Pengenalan Baju Adat Nusantara Dengan Metode Incremental. Indonesian Journal on Networking and Security, 7(4), 51-56.

Syarif, M., \& Nugraha, W. (2019). Metode incremental dalam membangun aplikasi identifikasi gaya belajar untuk meningkatkan hasil belajar siswa. Jusikom: Jurnal Sistem Komputer Musirawas, 4(1), 43-50.

Waseso, B., Wahab, A., \& Daryanto, T. (2018). PERANCANGAN SISTEM PEMANTAU KAPAL PERIKANAN (SPKP) UNTUK KAPAL DI BAWAH 30 GT DENGAN METODE INCREMENTAL. Incomtech, 7(1), 25-30.

Zulhartati, S. (2010). Peran Koperasi Dalam Perekonomian Indonesia. Guru Membangun. Media.Neliti.Com. 